\title{
Sensory Acceptability of Sorghum Peanut Blend (SPB) and Corn Soy Blend Plus (CSB + ) By Young Children With Moderate Acute Malnutrition in Karamoja, Uganda
}

\author{
Andrew Kiri Amegovu ${ }^{1}$, Patrick Ogwok ${ }^{2}$, Sophie Ochola ${ }^{1}$, Peter Yiga ${ }^{2}$, Juliet Hatoho Musalima ${ }^{2} \&$ \\ Juliana Mandha ${ }^{2}$ \\ ${ }^{1}$ Department of Food, Nutrition and Dietetics, Kenyatta University, Kenya \\ ${ }^{2}$ Department of Food Technology, Kyambogo University, Uganda \\ Correspondence: Patrick Ogwok, Department of Food Technology, Faculty of Science, Kyambogo University, \\ Uganda. Tel: 256-772-647-968. E-mail: ogwokp@yahoo.com
}

Received: December 13, 2013 Accepted: January 9, 2014 Online Published: January 10, 2014

doi:10.5539/jfr.v3n2p17

URL: http://dx.doi.org/10.5539/jfr.v3n2p17

\begin{abstract}
Sorghum peanut blend (SPB) and corn soy blend plus (CSB+) are highly nutritious supplementary food products. $\mathrm{SPB}$ is formulated using local food items while $\mathrm{CSB}+$ is a traditional product donated by World Food Programme to malnourished children in Uganda. The acceptability of SPB and CSB+ among children and caretakers was studied in northeastern Uganda. A 5-point hedonic scale was used to evaluate the caretakers' sensory preferences for the two supplementary diets. A four-day central tasting, two weeks home use trial, and exit interviews were carried out. Sensory attributes of both food supplements had a rank of $>4$. Taste varied $(P<$ $0.05)$ with the food type. $\mathrm{CSB}+$ had a higher $(P<0.05)$ taste score than SPB. Other attributes were not statistically different. During central tasting, about $100 \%$ of the served porridge was consumed by the children. Feeding duration of $300 \mathrm{~mL}$ of porridge was $8.14 \mathrm{~min}$ for CSB+ and $8.24 \mathrm{~min}$ for SPB. Over the two weeks home use trial, $98.4 \%$ of SPB and $98.1 \%$ of CSB + of the provided rations were consumed. The quantities of food consumed were above the recommended acceptability level of $\geq 75 \%$. Reported allergic and intolerance cases were below the $10 \%$ threshold. Both food supplements were found to be acceptable to children.
\end{abstract}

Keywords: corn soy blend plus (CSB+), sorghum peanut blend (SPB), acceptability

\section{Introduction}

Moderate acute malnutrition (MAM) is estimated to affect $11 \%$ of children worldwide (Black et al., 2008). World Food Programme (WFP) defines malnutrition as "a state in which the physical function of an individual is impaired to the point where he or she can no longer maintain adequate bodily performance process such as growth, pregnancy, lactation, physical work and, resisting and recovering from disease" (WFP, 2000). A malnourished child, hence, experiences slow physical and cognitive development and stands a greater risk of morbidity and death than their normal counterparts (WFP, 2000; Fishman, 2003). Poverty remains the major contributor to this poor health among children in sub-Saharan Africa. Traditional complementary foods are generally deficient in vital micronutrients as well as macronutrients (Eka, Abbey, \& Akaninwor, 2010). Lack of education especially among women further disadvantages the vulnerable children in delivery of healthy practices like breastfeeding and consumption of nutritious foods.

Promotion of local foods through nutrient evaluation and formulations is important when addressing malnutrition in low income countries. The high cost of implementing programmes that provides fortified blended food supplements to malnourished children makes them unaffordable by poor countries (De Pee \& Bloem, 2009; Muhimbula, Issa-Zacharia, \& Kinabo, 2011). As a result, these countries have depended on food aid for decades. It is nowadays important to adopt a horizontal approach in implementing programmes at community level. Sociocultural background of each community is therefore an essential baseline consideration for implementing nutrition health promotion programs. For instance, various strategies for 'home' fortification, or point-of use fortification, have been developed to ensure adequate micronutrient intakes by infants and young children (Nestel et al., 2003). 
Uganda is among the poorest communities of the world. For decades, Karamoja sub-region found in northeastern Uganda has depended on food aid from WFP and other UN development partners. Despite the timely and persistent nutritional intervention by WFP, the region is still faced with recurrent critical malnutrition rates (UDHS, 2011). Recurrence of acute malnutrition among children has remained endemic. At the moment, WFP and development partners are putting emphasis on use of broad based approach in management of malnutrition in Uganda. Formulations using local food materials have been proposed as a means of averting nutrient deficiency among young children in developing countries (Allen, 2003). Sorghum, peanut, ghee and honey could be exploited since they are easy to access in the region. The product could be prepared at home and used together with $\mathrm{CSB}+$, especially during food pipeline breakdown to avoid relapses. Using optifood tool, a local food supplement was formulated from sorghum, peanut, honey and ghee. CSB+, currently used as a supplementary food in Karamoja, was obtained from WFP Uganda. The sensory acceptability of SPB and CSB + by children and mothers was studied for treatment of MAM in children below five years of age.

\section{Materials and Methods}

\subsection{Preparation and Formulation of Sorghum Peanut Blend}

Raw materials used for formulation of SPB comprised of sorghum, groundnuts, ghee and honey. These food materials were locally procured from markets in northeastern Uganda. Sorghum and groundnuts were sun dried for five days to moisture levels below $10 \%$. Sorghum was cleaned by winnowing to remove damaged kernels, non grain plant materials and any other extraneous matter. Dirt free sorghum was then milled into flour. Groundnuts were hand sorted to remove damaged and shriveled kernels and any foreign matter. The groundnuts were roasted for 30 minutes using a charcoal stove before grinding to a semi-coarse paste. Milk from Karamajong Zebu cows was traditionally processed by fermentation for three days in pots. Fermented milk was churned by hand in a plastic jerry-can until butter granules clumped on the top. The butter granules were scooped off, washed to remove the butter milk and then matured for one week to develop the desired flavor. The ghee was boiled using a charcoal stove for 30 minutes to destroy microorganisms. Nutrisurvey computer software, employing linear programming technique, was used to generate appropriate component ratios (Erhardt, 2007). The quantity of each raw material depended on composition and the recommended daily allowances (Golden, 2009) for children between 6 to 59 months of age. Nutrient and anti-nutrient contents were analyzed to ascertain the nutritional adequacy of SPB and CSB+ (Table 1).

Table 1. Nutrient composition of Sorghum peanut blend and Corn soy blend plus per 100g

\begin{tabular}{lllll}
\hline & \multirow{2}{*}{ CSB +} & SPB & \multicolumn{2}{l}{ Recommended levels for MAM } \\
\cline { 5 - 6 } & & & Food based & Complement based \\
\hline Energy (kcal/100g) & 421 & 430 & 380 & 380 \\
Protein (\%) & 16.81 & 14.57 & $24 \mathrm{~g} / 1000 \mathrm{kcal}$ & $24 \mathrm{~g} / 1000 \mathrm{kcal}$ \\
Fat (\%) & 10.69 & 18.15 & $35 \mathrm{~g} / 1000 \mathrm{kcal}$ & $35 \mathrm{~g} / 1000 \mathrm{kcal}$ \\
Iron (mg) & 16.67 & 12.08 & 9 & 18 \\
Calcium (mg) & 891.6 & 737.5 & 600 & 840 \\
Magnesium (mg) & 71.83 & 86.83 & 200 & 300 \\
Sodium (mg) & 27.5 & 30.41 & 550 & 550 \\
Manganese (mg) & 0.73 & 2.14 & 1.2 & 1.2 \\
Zinc (mg) & 4.15 & 1.74 & 13 & 20 \\
Phosphorous (mg) & 485 & 380 & 600 & 900 \\
Potassium (mg) & 626.67 & 371.67 & 1400 & 1600 \\
\hline
\end{tabular}

Source: Amegovu et al., 2013. CSB+: Corn-soy blend; SPB: Sorghum-peanut blend; recommended levels for MAM are based on Golden 2009. Recommended levels for minerals are based on mg/1000kcal.

\subsection{Study Area}

Karamoja region was selected in northeastern Uganda for the study. One outpost attached to Nakapiripirit Health centre III was chosen. The inhabitants are predominately nomadic pastoralists. It is a semi arid region with a 
uni-modal rainfall season meaning one annual harvest. Karamoja is always dry, hot with heavy but short rainfall seasons. Prevalence of malnutrition in Karamoja is always above 10\% threshold (UDHS, 2011).

\subsection{Eligibility and Ethical Approval}

Inclusion criteria were children aged 12 to 59 months. A mid upper arm circumference (MUAC) tape was used to measure MUAC while birth certificates and age calendars were used to confirm the age. Children were excluded if they had a MUAC $<11.5 \mathrm{~cm}$, presence of edema, severe illness, and all those already participating in another clinical trial. Additionally, those with peanut, ghee or honey allergy were excluded from the study. A small dosage of supplement was given to the child and observed at least one hour for any allergic reactions. Ethical approval was obtained from the ethical committee of Uganda National Council of Science and Technology and the Ministry of Health. Caretakers signed an approval form as an informed consent to participate.

\subsection{Study Design and Data Collection Methods}

The study was done in two phases; the four days test feeding trial and a two week home use trial. Test feeding trail involved ranking the porridges by caretakers according to Meilgaard et al. (2007). It was conducted for four days; day one was orientation while the subsequent days involved actual tasting of the supplements. Orientation involved general introduction of food supplements to caretakers; formulations, preparation methods, consumption, and general purpose. In addition, cooking demonstrations, initial tasting of the porridge and completion of the questionnaire (hedonic scale) were conducted. Socio-economic and demographic data of participants was also collected. The second part of this phase involved child feeding trial. Caretakers prepared the porridges, tasted and fed the children at a central point. The color, taste, aroma, mouthfeel, consistency and overall acceptability of prepared porridges were evaluated based on a 5-point hedonic scale (Meilgaard et al., 2007). On the first day, mothers and caretakers were sensitized on procedures regarding supplementary feeding. By use of a cross-over design, children were randomized to receive one of the two study foods, SPB (n=21) and $\mathrm{CSB}+(\mathrm{n}=21)$ on the second day. This was followed by a one-day washout on the third day after which they were switched to the second food type on the fourth day. Each caregiver was provided with $300 \mathrm{~mL}$ (made by mixing $290 \mathrm{~g}$ of SPB and $269 \mathrm{~g}$ of CSB+ in $1 \mathrm{~L}$ of water) of porridge in a graduated cup to feed the child. During this time, it was ensured that the child was awake, alert, and calm but not drowsy or crying. The actual time each child took to drink the porridge or refused further feeding was recorded. Likewise, the amount taken was recorded by noting the remaining amount of porridge in the cup. Caretakers ranked the children's degree of liking basing on their perceptions. They also reported if the child vomited within the next hour or developed diarrhea and any reaction to the test meal.

During the second phase, mothers were given $2.03 \mathrm{~kg}$ of SPB (packaged in daily rations of $290 \mathrm{~g}$ ) and $1.883 \mathrm{~kg}$ of $\mathrm{CSB}+$ (packaged in daily ration of $269 \mathrm{~g}$ ) of flour for weekly visits made to the outpost. To avoid bias, food supplements were distributed randomly without putting into consideration caretakers' and Childs' preference. A qualitative and quantitative assessment of food supplement used and amounts consumed were noted. Only participants who completed the test feeding phase were eligible. To ensure that beneficiaries consumed the entire daily ration, caretakers were cautioned to feed the children on the products three times a day. Daily rations were separated into three portions, whereby one portion could be taken in the morning while others would be taken in the afternoon and evening hours. Proper storage conditions (room temperature) and preparation methods were well laid down. Village health teams visited the participants on a daily basis to check the amount of supplements consumed and to assess any difficulty encountered. At the end of the first week of supplementation, participants were visited to check the proportion of food remaining and inquire about any illnesses. At the end of second week, each child was visited to repeat the morbidity questionnaire and conduct an exit interview. This included quantity of food consumed, frequency of food intake and ease of preparation. In addition, open-ended questions were presented to explore the caretakers' views about other characteristics of the food supplements.

\subsection{Criteria for Food Supplement Acceptability}

A food supplement was deemed acceptable if a child consumed at least $75 \%$ of the serving and if less than $10 \%$ of adverse effect cases were reported (Valid International, 2006).

\subsection{Food Supplement Costing}

The costing of SPB was determined according to the prevailing local market food prices. Price of each raw material in local currency (Uganda shillings) was computed in relation to its proportion in the final product and summed up to obtain total cost of a kilogram of the food supplement. The price in local currency was then converted into United States dollars. The USA dollar was rated at Ugandan shillings 2600. WFP (2013) FOB Kampala, Uganda food commodity price was used for CSB+. 


\subsection{Data Analysis}

Data was analyzed using computer statistical software of SPSS 17.0. Differences between means of sensory parameters; color, aroma, taste, mouth feel, consistency, overall acceptability and children's' degree of liking were tested for significance using the least significance difference (LSD) at $95 \%$ confidence level $(P<0.05)$. Mothers' comments were also recorded verbatim and organized into themes.

\section{Results}

\subsection{Baseline, Demographic and Anthropometric Information}

Forty two sets comprising of a child and caretaker or mothers were recruited. The proportion of boys was $57.1 \%$ while girls made-up $42.9 \%$ of the total sample (Table 2). The mean age of mothers and caretakers, and children was 28.9 years and 34.8 months, respectively. Children had an average mid upper arm circumference (MUAC) of $12.1 \mathrm{~cm}$. The majority $(85.7 \%)$ of children had mothers while $14.3 \%$ were caretakers. No parent had attained tertiary education level. A sizeable number (57\%) of caretakers had not received any formal education. About $33.3 \%$ of mothers and caretakers whose documents could be verified had attended primary education. However, few $(9.5 \%)$ mothers and caretakers had completed primary education and the same number had attended secondary school education. No mother or caretaker had completed secondary education.

Table 2. Demographic, anthropometric and socioeconomic characteristics of participants

\begin{tabular}{|c|c|c|c|}
\hline & Mean \pm SD & Number $(\mathrm{N}=42)$ & $\%$ \\
\hline Age of children (months) & $34.80 \pm 9.65$ & & \\
\hline Weight (Kg) & $10.23 \pm 1.92$ & & \\
\hline Height (cm) & $87.75 \pm 10.54$ & & \\
\hline Mid upper arm circumference $(\mathrm{cm})$ & $12.1 \pm 0.34$ & & \\
\hline Weight-height Z score (WHZ) & $-2.28 \pm 0.50$ & & \\
\hline Average age of caretakers (years) & $28.9 \pm 6.60$ & & \\
\hline \multicolumn{4}{|l|}{ Sex of children } \\
\hline Male & & 24 & 57.1 \\
\hline Female & & 18 & 42.9 \\
\hline \multicolumn{4}{|l|}{ Respondents' relationship to child } \\
\hline Mother & & 36 & 85.7 \\
\hline Caretaker & & 6 & 14.3 \\
\hline \multicolumn{4}{|l|}{ Education level of mothers/ caretakers } \\
\hline No formal education & & 24 & 57.2 \\
\hline Primary level completed & & 4 & 9.5 \\
\hline Primary level dropouts & & 10 & 23.8 \\
\hline Secondary level completed & & 0 & 0 \\
\hline Secondary level dropouts & & 4 & 9.5 \\
\hline Tertiary level & & 0 & 0 \\
\hline
\end{tabular}

\subsection{Sensory Evaluation by Mothers and Caretakers}

The taste of porridge from corn soy blend plus $(\mathrm{CSB}+)$ was ranked higher $(P<0.05)$ than that of sorghum peanut blend (SPB) (Table 3). There were no significant differences $(P<0.05)$ in colour, aroma, mouth feel and consistency between the two supplementary diets. Sensory scores for all attributes were greater than four on a five-point scale. Caretakers perceived that children strongly liked both CSB + and SPB. Perceptions based on the degree of liking of the porridges by the children were deduced from the non-verbal cues exhibited during feeding. Maternal observation and interpretation of the Childrens' response to porridge served was translated into the degree of liking. Both products were strongly liked by the children (Table 4). 
Table 3. Sensory evaluation of the corn soy blend plus and sorghum peanut blend porridges by mothers

\begin{tabular}{llll}
\hline Attributes & CSB + & SPB & $P$-Value \\
\hline Color & $4.76 \pm 0.43$ & $4.57 \pm 0.59$ & 0.258 \\
Aroma & $4.33 \pm 0.48$ & $4.29 \pm 0.64$ & 0.815 \\
Taste & $4.81^{\mathrm{a}} \pm 0.40$ & $4.33^{\mathrm{b}} \pm 0.73$ & 0.009 \\
Mouth feel & $4.28 \pm 0.46$ & $4.38 \pm 0.66$ & 0.605 \\
Consistency & $4.24 \pm 0.44$ & $4.05 \pm 1.36$ & 0.493 \\
Overall acceptability & $4.71 \pm 0.46$ & $4.48 \pm 0.51$ & 0.649 \\
Child's degree of liking & $4.76 \pm 0.43$ & $4.57 \pm 0.59$ & 0.258 \\
\hline
\end{tabular}

$\mathrm{CSB}+$ : Corn soy blend plus. SPB: Sorghum peanut blend. "Values in rows with different superscripts are significantly different $(P<0.05), \mathrm{N}=42$.

Table 4.Cornsoy blend plus and sorghum peanut blend preferences of mothers by study product

\begin{tabular}{|c|c|c|}
\hline Attributes & $\mathrm{CSB}+$ & SPB \\
\hline \multicolumn{3}{|l|}{ Mother's perception of child's degree of liking (\%) $\dagger$} \\
\hline Like it a lot & $12(57.1)$ & $10(46.7)$ \\
\hline Like it & $8(38.1)$ & $10(46.7)$ \\
\hline Indifferent & $1(4.8)$ & $1(4.8)$ \\
\hline Do not like it & $0(0.00)$ & $0(0.00)$ \\
\hline Do not like it at all & $0(0.00)$ & $0(0.00)$ \\
\hline \multicolumn{3}{|l|}{ Mother's degree of liking $(\%) \dagger$} \\
\hline Like it a lot & $15(71.4)$ & $10(47.6)$ \\
\hline Like it & $6(28.6)$ & $11(52.4)$ \\
\hline Indifferent & $0(0.00)$ & $0(0.00)$ \\
\hline Do not like it & $0(0.00)$ & $0(0.00)$ \\
\hline Do not like it at all & $0(0.00)$ & $0(0.00)$ \\
\hline
\end{tabular}

$\mathrm{CSB}+:$ Corn soy blend plus. SPB: Sorghum peanut blend. $\uparrow$ Degree of liking assessed by a 5-point hedonic scale.

\subsection{Quantity of Food Consumed}

During the four day feeding trial, children consumed all the provided porridge regardless of the food type (Table 5). No significant variation was observed between the consumption quantities of the two food supplements. During test days 2 and 4 , children consumed more than $95 \%$ of the $300 \mathrm{~mL}$ of porridge (Table 5). The average duration of consumption was $8.14 \pm 1.50 \mathrm{~min}$ for CSB + and $8.24 \pm 1.54 \mathrm{~min}$ for SPB. No statistical difference $(P$ $<0.05$ ) was observed between the duration of consumption. Similarly, the velocity ( 37 to $38 \mathrm{~mL} / \mathrm{min}$ ) of food intake did not differ between the food types (Table 5). Over $95 \%$ of the given ration was consumed during the two week home use trial (Figure 1). A number of children ( $81 \%$ on SPB and 90.5\% CSB+) were fed three times a day. No mother or caretaker reported feeding a child on SPB and CSB + once a day. 
Table 5. Consumption of corn soy blend plus and sorghum peanut blend by young children

\begin{tabular}{|c|c|c|c|}
\hline Attributes & $\mathrm{CSB}+$ & SPB & $P$-Value* \\
\hline \multicolumn{4}{|l|}{ Amounts consumed } \\
\hline Day $2(\mathrm{~mL})$ & $297.38 \pm 3.75$ & $295.48 \pm 3.80$ & 0.88 \\
\hline Day 4 (mL) & $296.90 \pm 3.70$ & $297.14 \pm 4.05$ & 0.833 \\
\hline Pooled (mL) & $297.14 \pm 3.67$ & $296.31 \pm 3.99$ & 0.291 \\
\hline \multicolumn{4}{|l|}{ Feeding duration } \\
\hline Day 2 (min) & $8.19 \pm 1.50$ & $8.33 \pm 1.59$ & 0.379 \\
\hline Day 4 (min) & $8.09 \pm 1.51$ & $8.14 \pm 1.52$ & 0.815 \\
\hline Pooled (min) & $8.14 \pm 1.50$ & $8.24 \pm 1.54$ & 0.456 \\
\hline \multicolumn{4}{|l|}{ Velocity of food intake } \\
\hline Day $2\left(\mathrm{~mL} \mathrm{~min}^{-1}\right)$ & $37.15 \pm 8.27$ & $37.44 \pm 7.98$ & 0.247 \\
\hline Day $4\left(\mathrm{~mL} \mathrm{~min}{ }^{-1}\right)$ & $37.85 \pm 8.03$ & $38.07 \pm 7.91$ & 0.058 \\
\hline Pooled $\left(\mathrm{mL} \min ^{-1}\right)$ & $37.51 \pm 8.09$ & $37.76 \pm 7.86$ & 0.66 \\
\hline
\end{tabular}

$\mathrm{CSB}+$ : Corn soy blend plus. SPB: Sorghum peanut blend. *The level of significance for all tests is $P<0.05$. Day 1 result is not presented since it was orientation to allow mothers, caretakers and children adjust to protocol and the study environment. Day 3 was for washout.

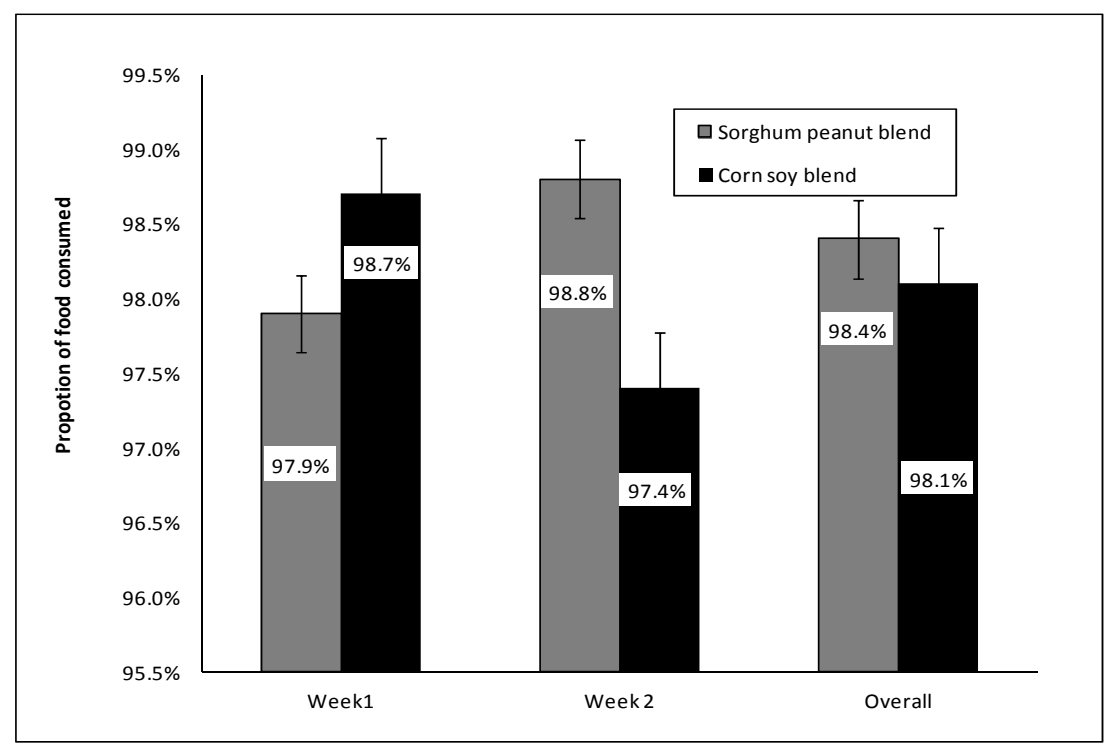

Figure 1. Proportion of food consumed over the two weeks home use in relation to the given ration

\subsection{Food Tolerance}

No major adverse effects were reported in relation to consumption of the two food supplements. No vomiting and allergic reactions were reported. Fever (4.8 to $9.5 \%$ ) and loss of appetite (4.8 to $9.5 \%$ ) were below $10 \%$ among children feeding on SPB and CBS+ but was not in any way related to the supplement. A lower percentage (4.8\%) of children fed porridge experienced diarrhea in the SPB group while none on CSB + was reported. Acute respiratory infections were relatively high (14 to $19 \%$ ) among children on both supplements. The prevalence of illnesses among children on CSB+ and SPB were within the range reported during the baseline study. Other allergic reactions including stomach-ache were not reported by mothers during the feeding period.

\subsection{Focus Group Discussions}

During focused group discussions (FGD), $98 \%$ of the 42 mothers and caretakers agreed that CSB+ and SPB prevented hunger and led to increment in weight of their young children. This made them consider SPB 
utilization to be a form of treatment for their malnourished and sickly children (Table 6). The taste of SPB and $\mathrm{CSB}+$ was appreciated as very good by mothers. CSB + was considered sweeter than SPB by mothers and caretakers although this could not be established statistically. All mothers and caretakers found it easy to prepare the porridge (Table 6).

Table 6.Participants perceptions towards sorghum peanut blend (SPB) and corn soy blend plus (CSB+)

\begin{tabular}{lllll}
\hline \multirow{2}{*}{ Response } & \multicolumn{2}{l}{$\mathrm{SPB}(\mathrm{N}=21)$} & \multicolumn{2}{c}{$\mathrm{CSB}+(\mathrm{N}=21)$} \\
\cline { 2 - 6 } & $\mathrm{N}$ & $\%$ & $\mathrm{~N}$ & $\%$ \\
\hline Views regarding preparation method & & & & \\
Easy & 21 & 100 & 21 & 100 \\
Difficult & 0 & 0 & 0 & 0 \\
Willingness to continue feeding the child & & & & \\
No & 0 & 0 & 0 & 0 \\
Yes & 21 & 100 & 21 & 100 \\
Supplement beneficial to the child & & & & \\
No & 0 & 0 & 0 & 0 \\
Yes & 21 & 100 & 21 & 100 \\
Negative and adverse effects & & & & \\
No & 21 & 100 & 21 & 100 \\
Yes & 0 & 0 & 0 & 0 \\
\hline
\end{tabular}

\subsection{Food Costing}

Basing on computations, the cost of materials required for SPB formulation is US\$ $0.81 / \mathrm{kg}$ while CSB+ is at US\$ $0.83 / \mathrm{kg}$ (WFP, Uganda FOB price, 2013). No significant difference was noted between the costs of the two products. The project implementation cost for distribution of CSB+ to beneficiaries would be the major factor in cost differences. This may be very costly when transportation and other subsidies are considered. Sorghum and peanut are staple foods in most parts of Uganda particularly Karamoja sub region. Ghee and honey were the most expensive raw materials in the local market but are common household commodities in Uganda.

\section{Discussions}

Sensory preferences of corn soy blend plus ( $\mathrm{CSB}+)$ and sorghum peanut blend (SPB) were acceptable by mothers and caretakers. No significant differences $(\mathrm{p}<0.05)$ were noted between the sensory qualities, except for taste, of the two supplementary foods. The appearance, aroma, taste and mouth feel of food products strongly correlates with the level of acceptance (Saba et al., 1998). The mean score for all sensory attributes for both CSB + and SPB porridges were $>4.0$ with no evidence of allergy. This signifies a general liking by infants and young children for the two supplementary foods.

$\mathrm{CSB}+$ and SPB were accepted by mothers and caretakers based on aroma and sweet taste. Olfactory preferences in infants and young children are learned, not innate and develop slowly (Bovell-Benjamin et al., 1999). Young children may detect 'unpleasant' smells, but may not judge them as 'unpleasant' until they are about 5 years of age (Mennella \& Bauchamp, 1997). Exposure will drive preference except in those cases when negative reactions from peers or parents teach young children that a given olfactory stimulus is unpleasant (Birch, 1992). Sweet taste has been demonstrated to have a positive effect on food product acceptability by children (Perez et al., 1994; Owino et al., 2007). This is supported by the fact that humans are born with innate preferences for sweet taste (Kern et al., 1993). CSB + had a better taste score than SPB. Sugar was used in the formulation of CSB+ while SPB contained honey. Tastes of SPB and CSB + were both within the acceptable range $(>4)$. Honey contains over $80 \%$ simple sugars contributing to the sweet taste of SPB (Gabriele Di Marco et al., 2012). In addition, it contributes to weight gain, digestibility, building immunity, and possess medicinal properties (Gabriele Di Marco et al., 2012). During focus group discussions, mothers proposed the use of sugar in SPB formulation instead of honey. This is possibly because it is easier to store sugar than honey. At the moment, a few households in Karamoja can afford sugar. Honey is a preferred sweetener for local formulation being a household commodity. However, sugar could 
be used by families that can afford it.

Food consistency score ( $>4$ ) of porridges prepared from CSB + and SPB were appropriate for supplementary foods for infants and children (Brown, Dewey, \& Allen, 1998). Consistency of supplementary foods has been demonstrated to have a direct correlation with preference among children (Parker et al., 1998). A thick porridge would require more effort to swallow limiting its intake by young children (King \& Ashworth, 1987). A thin porridge means low energy density which is also undesirable. A semi-liquid porridge is appropriate for feeding infants and children on cereal-based foods (Codex, 1981).

During the two-week feeding trial, no side effect relating to consumption of the two supplementary foods was reported. Diarrhea, fever and acute respiratory infection (ARI) were reported by some mothers and caretakers. It is however difficult to associate specific illnesses and side effects on consumption of a particular food. The highest prevalence of illnesses was reported for ARI but this was not in any way related to the food supplements as supported by the baseline study. Diarrheal cases reported during the study period were related to fever. It is recommended that the number of allergic and intolerance cases towards food products, should not exceed $10 \%$ (Bovell-Benjamin et al., 1999). In this study, all cases reported were below the $10 \%$ threshold required to declare a product to have adverse effects even though it may not be associated with consumption of CSB+ and SPB. Overall, focus group discussions with mothers and caretakers strongly indicated preference for the two supplementary products.

CSB + and SPB were 'liked a lot' or generally 'liked' by the children as indicated by the quantities consumed in a short time (Table 4). Infants who lack adequate food may eat eagerly without preference but because of hunger. $\mathrm{CSB}+$ and SPB were considered beneficial by mothers and caretakers based on the noticeable weight gain. According to the focus group discussions and sensory scores, most mothers and caretakers were willing to continue feeding children on the two products (Table 6). Cardello et al. (2000) and Markowitz (1991) have demonstrated that food consumption behaviour is an index that assesses attitudes towards a food product. A person may like the product but may not be willing to consume it on a regular basis or in large amounts (Moskowitz, 1991). The amount of food consumed over a given period of time can be used to assess consumer behaviours towards a food product (Cardello et al., 2000). On the whole, the utilization of the two supplementary products during study period is indicative of product quality.

\section{Conclusion}

Sensory attributes of SPB were not inferior to those of CSB+. Both food supplements were acceptable by young children with no serious adverse health effects. Adequate amounts of SPB and CSB+ were consumed over the two weeks home trial. The two supplementary products could be used for management of moderate acute malnutrition based on the high sensory preferences.

\section{Acknowledgements}

This work is indebted to the mothers, caretakers and young children who willingly participated in the study. The research team is grateful to the research assistants, village health teams and health centre focal persons for their participation during enrollment and follow up of the children. Sincere thanks also go to World Food Progamme (Uganda), Andre Food Consult (Uganda) and the District Health Officer (Nakapiripirit district, Uganda). None of the authors had any conflict of interest to report.

\section{References}

Amegovu, K. A., Ogwok, P., Ochola, S., Yiga, P., Musalima, H. J., \& Mutenyo, E. (2013).Formulation of sorghum-peanut blend using linear programming for treatment of moderate acute malnutrition in Uganda. Journal of Food Chemistry and Nutrition, 1(2), 67-77. Retrieved from http://www.escijournals.net/JFCN

Birch, L. L. (1992). Children preference for high-fat foods. Nutrition Reviews, 50, 249-255. http://dx.doi.org/10.1111/j.1753-4887.1992.tb01341.x

Black, R. E., Allen, L. H., Bhutta, Z. A., Caulfield, L. E., de Onis, M., Ezzati, M., ... Rivera, J. (2008). Maternal and child under nutrition: global and regional exposures and health consequences. Lancet, 371, 243-60. http://dx.doi.org/10.1016/S0140-6736(07)61690-0

Bovell-Benjamin, A. C., Lindsay, H. A., \& Jean-Xavier, G. (1999). Toddlers' acceptance of whole maize meal porridge fortified with Ferrous Bisglycinate. Food Quality and Preference, 10, 123-128. http://dx.doi.org/10.1016/S0950-3293(98)00058-5

Brown, H. H., Dewey, K. G., \& Allen, L. H. (1998). Complementary feeding of young children in developing countries: a review of current scientific knowledge. World Health Organization, Geneva, WHO/NUT/98. 
Cardello, A. V., Schutz, H., Snow, C., \& Lesher, L. (2000). Predictors of food acceptance, consumption and satisfaction in specific eating situations. Food Quality and Preference, 11(3), 201-216. http://dx.doi.org/10.1016/S0950-3293(99)00055-5

Codex Alimentarius. (1981). Standard for Processed Cereal-Based Foods for Infants and Children. Codex Stan, 74. FAO, Rome.

De Pee, S., \& Bloem, M. W. (2009). Current and potential role of specially formulated foods and food supplements for preventing malnutrition among 6-23 months old and treating moderate malnutrition among 6-59 months old children. Food Nutrition Bulletin, 30(suppl), S434-63.

Di Marco, G., Canuti L., Impei, S., Leonardi, D., \& Canini, A. (2012). Nutraceutical properties of honey and pollen produced in a natural park. Agricultural Sciences, 3(2), 187-200. http://dx.doi.org/10.4236/as.2012.32022

Eka, B. E., Abbey, B. W., \& Akaninwor, J. O. (2010). Nutritional Evaluation of Some Traditional Weaning Foods from Akwalbom State, Nigeria. Nigerian Journal of Biochemistry and Molecular Biology, 25(1), 65-72.

Erhardt, J. Nutrisurvey software version 2007. [Updated 2012/04/04; cited 2007/08/08]; Retrieved from http://www.nutrisurvey.de.

Fishman, S. C. L., De Onis, M., Blossner, M., Mullany, L., \& Black, R. E. (2003). Malnutrition and the global burden of disease: underweight. Cambridge, MA: World Health Organization/Harvard University Press.

Golden, M. (2009). Proposed nutrient requirements of moderately malnourished populations of children. Food Nutrition Bulletin, 30, S237-S342.

Kern, D. L, Mcphee, L., Fisher, J., Johnson S., \& Birch, L. L. (1993). The postingestive consequences of fat condition preferences for flavors associated with high dietary fat. Physiological Behaviour, 54, 71-76. http://dx.doi.org/10.1016/0031-9384(93)90045-H

Kevin, K. (1995). You've come a long way, baby-food! Food Process, 56(2), 61-64.

King, J., \& Ashworth, A. (1987). Changes in infant feeding practices in Nigeria, a historical review occasional paper No. 9 London: Centre for Human Nutrition, London School of Hygiene and Tropical Medicine.

Meilgaard, M., Civille, G. V., \& Carr, B. T. (2007). Sensory evaluation techniques (4th ed. Chapter 12, pp. 225-311). CRC Press, Boca Raton, FL.

Mennella, J. A., \& Bauchamp, G. K. (1997). Mothers' milk enhances the acceptance of cereal during weaning. Pediatric Research, 41(2), 188-92. http://dx.doi.org/10.1203/00006450-199702000-00006

Moskowitz, H. R. (1991). Optimizing consumer product acceptance and perceived sensory quality. In E. Graf \& I. S. Saguy (Eds.), Food product development: From concept to the marketplace(pp. 157-188). New York: Van Nostrand Reinhold. http://dx.doi.org/10.1007/978-1-4613-0675-7_8

Muhimbula, H. S., Issa-Zacharia, A., \& Kinabo, J. (2011). Formulation and sensory evaluation of complementary foods from local, cheap and readily available cereals and legumes in Iringa, Tanzania. African Journal of Food Science, 5(1), 26-31.

Nestel, P., Briend, A., De Benoist, B., Decker, E., Ferguson, E., Fontaine, O., ... Nalubola, R. (2003). Complementary food supplements to achieve micronutrient adequacy for infants and young children. Journal of Pediatric Gastroenterology and Nutrition, 36, 316-328. http://dx.doi.org/10.1097/00005176-200303000-00005

Owino, V. O., Sinkala, M., Amadi, B., Tomkins, A., \& Filteau, S. M. (2007). Acceptability, storage stability and costing of $\alpha$-amylase-treated maize-beans-groundnuts-bambaranuts complementary blend. Journal of the Science of Food and Agriculture, 87, 1021-1029. http://dx.doi.org/10.1002/jsfa.2799

Parker, M. E., Schroeder, D. G., Begin, F., \& Hurtado, E. (1998). Maternal preferences for consistency of complementary foods in Guatemala. Food and Nutrition Bulletin, 19, 6-12.

Perez, C., Dalix, A. M., Guy-Grand, B., \& Bellisle, F. (1994). Human responses to five concentrations of sucrose in a dairy product: immediate and delayed palatability effects. Appetite, 23, 165-178. http://dx.doi.org/10.1006/appe.1994.1044

Saba, A., Moneta, E., Nardo, N., \& Sinesio, F. (1998). Attitude, habit, sensory and liking expectation as determinants of the consumption of milk. Food Quality and Preference, 9, 31-41. http://dx.doi.org/10.1093/chemse/13.2.145 
UDHS. (2011). Uganda Demographic and Health Survey. Uganda Bureau of Statistics Kampala, Uganda. MEASURE DHS project, ICF International, Calverton, Maryland, USA.

Valid International. (2006). Community Based Therapeutic Care (CTC). A Field Manual (1st ed.). ValidInternational. $\quad$ Oxford.

http://www.concernusa.org/media/pdf/2007/10/CTC_Manual_v1_Oct06.pdf

WFP. (2000). World Food Programme of United Nations. Food and Nutrition Handbook. Rome, Italy.

\section{Copyrights}

Copyright for this article is retained by the author(s), with first publication rights granted to the journal.

This is an open-access article distributed under the terms and conditions of the Creative Commons Attribution license (http://creativecommons.org/licenses/by/3.0/). 